\title{
Youth reproductive health: Investing in the future
}

Frontiers in Reproductive Health

Follow this and additional works at: https://knowledgecommons.popcouncil.org/departments_sbsr-rh

Part of the Demography, Population, and Ecology Commons, Family, Life Course, and Society Commons, International Public Health Commons, Maternal and Child Health Commons, and the Medicine and Health Commons

How does access to this work benefit you? Let us know!

\section{Recommended Citation}

"Youth reproductive health: Investing in the future," FRONTIERS Legacy Themes. Washington, DC:

Population Council, 2009. 


\section{Population Council FRONTIERS \\ IN REPRODUCTIVE HEALTH}

\section{Legacy Series: YOUTH REPRODUCTIVE HEALTH}

\section{Investing in the Future}

Youth-young people aged 10-24-constitute about a quarter of the world's population, with nearly three-quarters living in the developing world, and they suffer a disproportionate share of unplanned pregnancies, STIs including HIV, and other reproductive health $(\mathrm{RH})$ problems. Research undertaken by the Frontiers in Reproductive Health Program (FRONTIERS) has shed light on numerous aspects of youth reproductive health, including information needs of young people, parents and guardians, and married adolescents. Findings from over 20 studies on youth $\mathrm{RH}$ provide important lessons about which interventions are effective, what kind of impact is possible, and what approaches have limited impact.

\section{Engaging All Stakeholders in Youth RH}

Use a multisectoral approach. Improving young people's knowledge of reproductive health, delaying sexual debut and ensuring safer sexual practices requires a holistic approach including and engaging all stakeholders, and not just youth. FRONTIERS tested a multisectoral approach in four countries - Bangladesh, Kenya, Mexico and Senegal designed to change young people's knowledge, attitudes, and behavior by mobilizing existing resources and institutions, and gaining community support. In each country, a three-pronged intervention was implemented primarily by government partners (through ministries of health, education, youth affairs, and social services) and with nongovernmental agencies: i) teachers and peer educators delivered country-specific reproductive health curricula for in- and out-of-school youth; ii) community, youth and religious leaders created supportive and enabling environments with public, cultural, and sports awareness-raising events; and iii) health workers addressed adolescent information and service needs in "youth-friendly spaces" at health facilities and within communities (Chege, Njue, and Radeny 2004; Bhuiya et al. 2004; Diop et al. 2004; Vernon and Durá 2005). 
Pre- and post-intervention surveys showed positive changes, often reaching statistical significance, at community level in all countries (Table 1), with variations among countries and among indicators. For example:

0 The proportion of youth knowing about contraceptives at endline was higher in Bangladesh (over 93\%) than in Senegal (80 to $86 \%$ ).

o Mexican youth who knew of contraception could name five or more methods without prompting, while only 17 to 40 percent of youth in Bangladesh could name two or more methods.

o In Bangladesh, use of health facilities increased tenfold in the intervention sites, while their use decreased in the Mexico intervention sites.

Table 1: Changes in Key Indicators Due to Reproductive Health Interventions

\begin{tabular}{|c|c|c|c|c|}
\hline & Bangladesh & Kenya & Mexico & Senegal \\
\hline \multicolumn{5}{|l|}{ Knowledge } \\
\hline HIV/AIDS & + & + & + & + \\
\hline Contraception & + & + & + & + \\
\hline Sexual and reproductive health & + & + & + & + \\
\hline Condoms & * & + & + & + \\
\hline Parental communication & + & + & + & + \\
\hline \multicolumn{5}{|l|}{ Attitudes } \\
\hline Approval of contraception & + & + & + & + \\
\hline \multicolumn{5}{|l|}{ Behavior } \\
\hline Sexual activity & $\mathrm{N} / \mathrm{C}$ & - & $\mathrm{N} / \mathrm{C}$ & - \\
\hline Use of health facilities & + & $\mathrm{N} / \mathrm{C}$ & - & + \\
\hline
\end{tabular}

+ indicates increase in indicator value associated with intervention; - indicates decrease in indicator value associated with intervention; N/C indicates no change; * indicates data not available (Adamchak 2003)+.

In Kenya, the interventions also appeared to be associated with a small but significant increase in mean age at sexual debut (Table 2) (Chege, Njue, and Radeny 2004).

Table 2: Median Age in Years at First Penetrative Sex Among All Sexually Active Adolescents, Kenya

\begin{tabular}{|c|c|c|c|c|c|c|}
\hline \multirow{2}{*}{} & \multicolumn{2}{|c|}{ Intervention sites A } & \multicolumn{2}{c|}{ Intervention sites B } & \multicolumn{2}{c|}{ Control sites } \\
\cline { 2 - 7 } & Baseline & Endline & Baseline & Endline & Baseline & Endline \\
\hline Boys & 13.9 & $14.3^{*}$ & 13.9 & $14.4^{*}$ & 13.9 & 14.1 \\
Girls & 15.1 & 15.4 & 14.5 & $15.0^{*}$ & 14.6 & 14.3 \\
\hline
\end{tabular}

Source: Askew, Chege, Njue, and Radeny 2004 
Encourage parent-child partnerships. Parents understand young people need information on reproductive health, but many are insufficiently informed themselves and often feel "shy" to do so (Diop and Diagne 2008; Bhuiya et al. 2004). Despite expressed desire for children to be informed about reproductive health, parents often have strong preferences regarding information they wish youth to learn - for example, preferring children learn about abstinence rather than contraception. Program managers must ensure interventions do not violate cultural norms, while at the same time communicating valid and helpful information (Chege, Njue and Radeny 2004; Diop and Diange 2008; Diop and Diagne 2007; IRESCO 2002).

Improving intergenerational dialogue is feasible. An intervention in Senegal used a multisectoral approach to enhance discussions between adults and their children or wards (Diop and Diagne 2008). Following separate youth and parent orientation sessions, both groups took part in intergenerational dialogues on topics such as gender, reproductive health, and HIV. Pre- and post-intervention surveys showed a significant increase in the proportion of youth comfortable discussing RH issues with their parents (increasing from $25 \%$ to $38 \%$ ), with a greater proportion reporting parents were willing to discuss reproductive health issues (from $80 \%$ to over $90 \%$ ). Moreover, after the intervention a much greater proportion of sexually active youth reported using protection during last sex ( $27 \%$ and $46 \%$ ). Parents and guardians were likely to tailor discussion of sexuality by child gender-discussing avoiding pregnancy with girls and talking more openly about HIV and STIs with boys. In this setting parents remained uncomfortable with discussions on contraception.

Engage peer educators to encourage youth leadership. Young people must play a part in design and implementation of youth reproductive health program. Senegal's multisectoral model created a sustainable partnership between existing, nationally recognized youth associations and public-sector health facilities, where peer educators conducted education and outreach (Diop et al. 2004). The most dynamic youth organizations were selected and provided with comprehensive training and refresher courses. In each organization youth were members of the project steering committee and contributed to study design and implementation from the planning stages. Ministry of Health staff officially introduced peer educators to participating communities, underlining the importance of young people's leadership. This approach resulted in high peer educator retention, many of whom are now training new peer educators and developing initiatives with other public and nongovernmental institutions.

Young people are willing, and in some settings prefer, to receive advice from peers; and the one-on-one contact between peer educator and client has been shown to be more effective in improving knowledge than group activities (Erulkar, Beksinka, and Cebekhulu 2001; Diop et al. 2004). Through individual and group activities, peer educators in a Senegal program reached 20,000 people during initial intervention and over 8,000 in subsequent expansion (Joyce et al. 2008). Youth educators were also effective in Cameroon, where 25 male and female peer educators received training to give talks and messages on healthy sexuality and distributed comic books and magazines on youth reproductive health. 
Pre- and post-intervention surveys of about 2,500 young people in the intervention and control areas showed reported abstinence increased in intervention sites (from $50 \%$ to $62 \%$ ), while decreasing in control areas (from 60\% to 56\%). Among girls exposed to the intervention, reported condom use with last partner increased significantly (from $44 \%$ to 79\%) (IRESCO 2002).

Incorporate RH education into tertiary-level curricula. In Bangladesh, the Ministry of Youth and Sports introduced reproductive health education into five of the country's 47 government-run vocational training centers. The 10-hour curriculum was adapted from the school-based curriculum developed for the Bangladesh multisectoral intervention, which included reproductive biology, family planning, STI prevention, and critical thinking and negotiation skills. About 450 male and female students aged 16 to 24 participated. Comparison of pre- and post-intervention scores showed significant increases in understanding of reproductive health, such as knowledge of a woman's fertile period (increasing from $27 \%$ to $79 \%$ ), the dual protection role of condoms (65\% to $89 \%$ ), and emergency contraception (42\% to 93\%). Knowledge of HIV prevention methods also increased significantly (Figure 1). They also cleared up a number of reproductive health "myths" - for example, the proportion of students

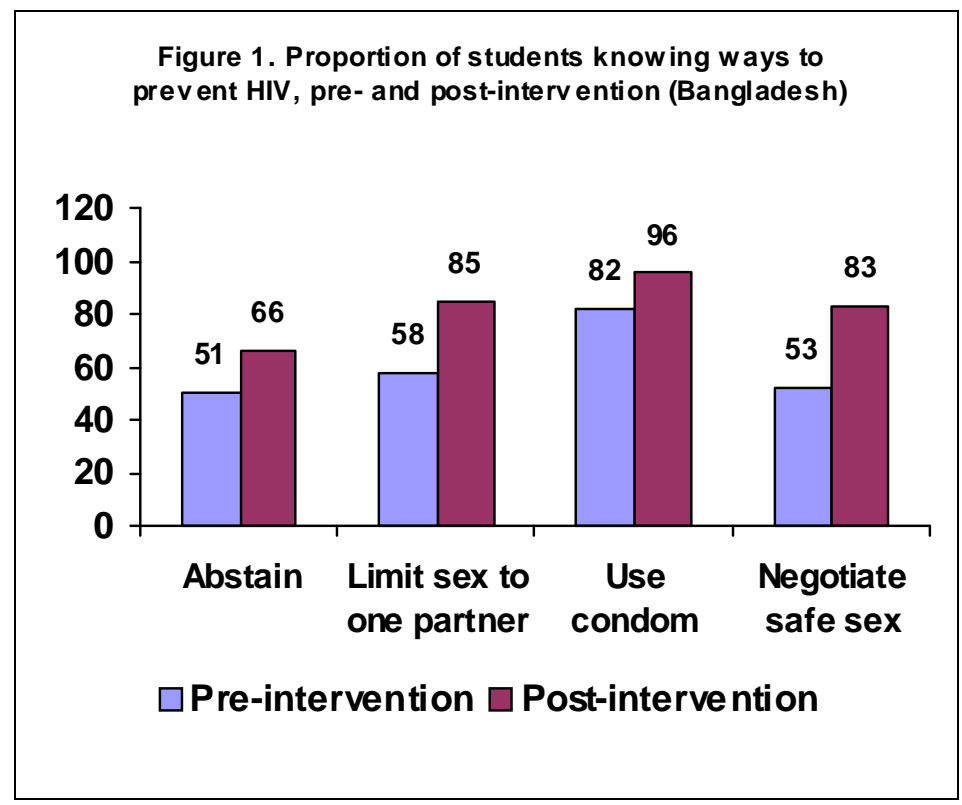
believing menstruation is a disease ( $42 \%$ down to $7 \%$ ). The intervention was scaled up into the remaining centers (Rahman et al. 2006).

Anticipate scale-up during project planning and implementation. The multisectoral models piloted in Kenya and Senegal proved successful enough to warrant scaling up to provincial and national levels. A full description of procedures followed is given elsewhere (Joyce et al. 2008). The successful scale-up of the models in Kenya and Senegal depended upon: i) direct and continuous involvement of the staff of all three government ministries in all phases of the pilot project; and ii) sustained technical assistance to help ministries identify and incorporate practices for scale-up within the each ministry's annual workplans, training strategies, and budgets. Institutionalizing youth $\mathrm{RH}$ activities within government ministries represents a significant organizational change and required a long-term commitment-over eight years - on the parts of ministries, donors and technical assistance organizations. Strategies for expanding these activities in both countries shared common elements but were tailored to local needs and conditions (see Box next page) (Evelia et al. 2008; Diop and Diagne 2007). 


\section{Institutionalizing RH Information and Services in Kenya and Senegal: Different Models, Shared Strategies}

Kenya: Phased replication and full scale-up of activities to all provinces

Senegal: Expansion of Senegal pilot model and export of model and implementation tools to Francophone African countries and beyond

Common elements in both countries:

- Identify RH and HIV prevention among youth as a national priority

- Identify and adapt cost-effective practices, tools, and materials that are ministry-specific

- Establish multisectoral bodies at several levels to guide activities

- Build the capacity of participating ministries to plan, budget for, and implement activities

- Incorporate RH and HIV prevention activities within routine ministerial functions

- $\quad$ Long-term commitment by ministries and donors

\section{Addressing Underserved Groups}

Address needs of married adolescents. Married adolescents, especially girls, are underserved, frequently inexperienced sexually before marriage and often with limited access to health services. Because they have sex, including unprotected sex, more frequently than unmarried girls, young wives may actually be more vulnerable to $\mathrm{RH}$ risks. As a first phase of a longer study, Population Council and local partners in Ethiopia and Kenya assessed feasibility of community-based interventions raising awareness of HIV risks in early marriage and promoting use of HIV counseling and testing (C\&T) services by couples. Interventions in both countries used similar strategies, such as engaging community religious leaders, promoting premarital C\&T and HIV services, and supporting young wives through married girls' clubs and mentoring programs. In both countries, mobilizing religious leaders proved an effective approach, reaching over 900,000 people in Ethiopia and 17,000 people in Kenya with supporting messages. Girls' clubs and mentoring schemes reached over 16,000 girls in Ethiopia, and between 2,500 and 7,500 married girls in Kenya attended meetings on HIV, C\&T, and HIV treatment. Findings from these feasibility studies are now guiding expansion of these models (Erulkar and Ayuka 2007; Erulkar and Mekbib Forthcoming).

In Nepal, FRONTIERS tested two models-village mothers' groups and youth communication action groups - for increasing access to $\mathrm{RH}$ information and services for young married women under age 25 . Both groups received training, educational materials about STIs and condoms, and help with outreach, and were encouraged to conduct outreach at special events and public meetings. Contraceptive prevalence increased modestly among the youth groups, but nearly doubled (from 19\% to 37\%) in mothers' group areas. The proportion of women who attended antenatal care also increased significantly (from $20 \%$ to $54 \%$ ) among mothers' groups. Knowledge about STIs and HIV increased significantly in both, especially youth (CREHPA 2005). 


\section{Using Research to Guide Youth Programming}

Youth centers have limited impact on youth reproductive health. Many programs have utilized youth centers as a key strategy for providing youth $\mathrm{RH}$ information and services. Studies in Ghana, Kenya, and Zimbabwe, however, showed that young people most often use informal venues, such as shops, kiosks, and friends, to obtain condoms and reproductive health information (Population Council 1999). Research in South Africa has shown youth centers are costly and largely ineffective in improving youth reproductive health, and establishing youth-friendly health facilities within these centers has had mixed success. Research conducted by Population Council and the South African Reproductive Health Research Unit in KwaZulu Natal province looked at the cost and reach of eight different centers. The study showed wide variation in annual costs-from a low of about US\$12,000 to a high of $\$ 80,000$. Center use varied from 50 to 450 visits weekly, and less than one-third of youths in center catchment areas had ever visited. Reproductive health services from nurses or peer educators accounted for a significant proportion operating costs; but information and services had little impact on young people's sexual behavior. Program managers interested in supporting youth centers should carefully consider goals of centers to ensure maximum cost-effectiveness (Erulkar et al. 2001; Janowitz et al. 2003).

Increasing RH knowledge does not lead to increased sexual activity. Multisectoral interventions in Bangladesh, Mexico, Kenya, and Senegal increased youth $\mathrm{RH}$ knowledge (Chege, Njue, and Radeny 2004; Bhuiya et al. 2004; Diop et al. 2004; Vernon and Durá 2005). In Kenya, young people exposed to the intervention reported less sexual activity of any kind than non-exposed youth (Figure 2).

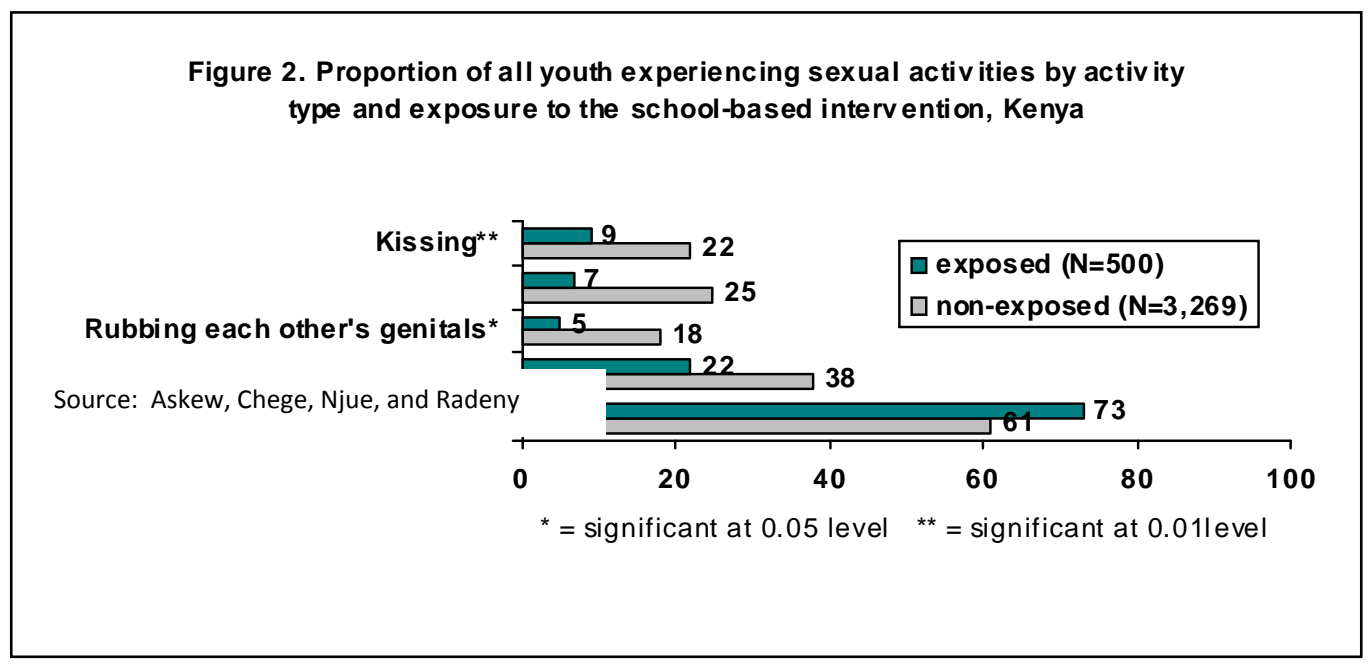

Youth exposed to a peer educator campaign were likely to have fewer partners, and were more likely to use a condom during sexual activity with casual

partners, showed a study in Cameroon (IRESCO 2002). Peer educators trained as part of an ARH intervention in Zambia reported they had changed their sexual behavior-mostly by abstaining - to reduce risk (Fetters, Mukonze, and Solo 1999). This evidence shows exposure to factual, accurate $\mathrm{RH}$ information does not promote more promiscuous attitudes and behaviors, as is often feared when such programs are first introduced. 